\title{
Amazônia:
}

\section{uma fronteira volátil}

\author{
ANTÔNIO CLÁUdio RABELLO
}

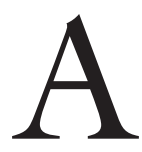

OCUPAÇão da Amazônia, através de projetos de desenvolvimento (a partir dos anos 1950) e de colonização (a partir dos anos 1970), levou pesquisadores a se debruçarem sobre a temática da fronteira. Alguns deles buscaram observar o fenômeno da ocupação e procuraram entender a dinâmica que norteava a expansão da fronteira. Outros optaram por outra abordagem, que privilegiou a compreensão da incorporação da Amazônia a partir de um patamar de análise, que não perdia de vista a luta política de então. Outras tentativas implicaram entender e caracterizar a fronteira em si ou a vida na fronteira. Vejamos algumas formulações.

\section{O imperialismo e a fronteira amazônica}

A tese acerca da ocupação da Amazônia de Ariovaldo Umbelino de Oliveira (1993) está baseada no cenário e nas disputas políticas do período militar, bem como o posicionamento desse regime em relação ao capital internacional. A base da sua interpretação é a divisão Internacional do Trabalho e o Imperialismo. A partir daí o autor buscou compreender, desde a República Velha até os governos militares, como se deu a construção do imperialismo norte-americano no Brasil, capitaneado pelas indústrias ligadas à área de mineração. Segundo ele, desde o comércio do Brasil com a Inglaterra, passando pela Itabira Iron Co., a relação do Brasil com o mercado internacional foi marcada pelos mandos e desmandos do capital internacional. Oliveira repensou a História Política do Brasil a partir dos interesses de grandes grupos privados norte-americanos e buscou trazer à tona a participação de personagens que ocupavam, ou passariam a ocupar, um lugar de destaque no Estado brasileiro e/ou nas grandes companhias multinacionais imperialistas (ibidem, p.25)

No tocante à Amazônia, a visão é a da incorporação ao capital nacional (por ele chamado de testa de ferro do capital internacional), ou mesmo diretamente ao capital internacional. Através de relatos de época, quando se constituiu a "Operação Amazônia” (anos 1960 e 1970), o autor tratou os governos militares como entreguistas - segundo ele, o lema “o que não entregar-se-á aos Estados Unidos entregar-se-á à União Soviética” explicava a ação do governo militar brasileiro - portanto, a ocupação da fronteira Amazônica foi vista a partir desse prisma. Sendo assim, todos os programas de colonização, de investimentos e de integração, como também todos os órgãos criados serviam a essa finalidade. 
Ao trazer à tona o relatório Velloso (CPI sobre o escândalo das terras vendidas ao exterior), salientou que na Amazônia havia $150.000 \mathrm{~km}^{2}$ nas mãos de estrangeiros. A saída dos militares, mais uma vez através de decreto, foi determinar que enormes faixas de terra ao longo das rodovias fossem consideradas áreas prioritárias para projetos de colonização e desenvolvimento.

O autor, apesar de centralizar sua análise na ação imperialista na Amazônia, considera os interesses no capital nacional e a forma como esse se comportou na Operação Amazônia. Citando a primeira "Reunião de Investidores da Amazônia", realizada em dezembro de 1966, Oliveira descreveu a frase do ex-deputado Sérgio Cardoso de Almeida (grande proprietário de terras da região de Araraquara - SP) de forma indignada. O deputado-empresário teria dito "Ao empresário interessa saber onde pode aplicar o seu dinheiro para ganhar mais dinheiro", conforme reportagem do jornal Folha de S.Paulo, de 16 de abril de 1967.

Que tipo de espanto e indignação essa frase poderia ter causado neste autor? A dinâmica de reprodução do capital é justamente essa. Na há como esperar uma atitude benevolente do capital em nenhuma parte do planeta, mesmo que essa parte do mundo seja a Amazônia. Toda e qualquer lógica de investimento de capital na região ou fora dela teve e terá como pressuposto a possibilidade de reproduzir-se, sempre, de forma ampliada.

O problema e o mérito da construção de Oliveira, ao tratar da expansão da fronteira amazônica, estão em atribuí-la aos interesses capitalistas internacionais. O problema consiste em não considerar outras dinâmicas existentes no processo de ocupação da Região Amazônica. Ao situar as relações imperialistas, para explicar o interesse do capital internacional (sobretudo norte-americano) na Amazônia, o autor deixou de lado as relações presentes na ocupação de terras na Amazônia, como a instalação de pequenos agricultores. Com certeza, os interesses sobre os minérios da região amazônica chamaram a atenção do capital internacional para investimentos na região (Garrido Filha, 1980), mas a possibilidade de aquisição de terras $(20,50,100$ ou 250 ha) não representa o anseio do capital internacional. O mérito consiste em não isolar a Amazônia ou o Brasil. A sua tentativa de compreender a região dentro de uma dinâmica da reprodução de capital e a inserção do Brasil e da Amazônia nesse cenário foi, sem dúvida, um mérito. Não há como compreender ou propor alternativas para a Amazônia, sejam elas ecológicas ou de desenvolvimento, sem considerar o sistema econômico-político que a circunda.

\section{Amazônia: fronteira aberta, porém controlada}

A tese de Otávio Guilherme Velho (1979) está centrada no processo de ocupação das terras ao longo da rodovia transamazônica, durante o Programa de Integração Nacional. Velho comparou o processo de expansão sobre a fronteira no Brasil e o nos Estados Unidos, dialogando com teóricos que se debruçaram sobre a temática. 
O problema, segundo o autor, é que tanto Moore Jr. como Turner tentam relacionar expansão da fronteira e democracia. Ao tratar de forma comparada da expansão da fronteira amazônica, nosso autor se vê num dilema. Como pensá-la, então, inserida em um processo de expansão controlado por um Estado autoritário? Seus resultados implicam contrapor-se às teses de Turner. Ele entendeu a fronteira fechada como mecanismo de controle da classe trabalhadora e construiu uma nova adjetivação para a fronteira amazônica no período: "fronteira aberta, porém controlada". Ele alertou para o fato de que, mesmo numa fronteira controlada, poderia acontecer o enfraquecimento da subordinação do camponês, o que geraria uma proximidade entre esses camponeses e os farmers americanos. Ressaltou, porém, que uma simples aproximação ou comparação não bastaria para identificar igualdades.

Outro aspecto que Velho ressaltou foi a noção de bem ilimitado. Citando George Foster, diz que o camponês tem uma visão da natureza enquanto um bem limitado; logo, o uso da terra, também o é. Em decorrência disso, a produção também é encarada como limitada. Para uma comunidade camponesa toda tentativa de mudança de status quo significaria desequilíbrio, pois onde um homem ganha, outro deverá perder. Ou seja, o progresso traria desigualdade, por isso Foster considerava-os como tradicionais. A conclusão, quando se coloca em questão a visão da fronteira como um bem ilimitado, é a de que a fronteira aberta seria o equivalente ao espaço primordial do laissez-faire. A reflexão de Velho nos conduz a outro impasse sobre a fronteira amazônica. Como considerar a expansão sobre a fronteira amazônica em um país que não poderia ser caracterizado como liberal (tanto no sentido econômico quanto no político)? Como entender a relação do Estado na expansão da fronteira, muitas vezes apontada como espaço de liberdade? Velho entendeu que para o campesinato a fronteira representava uma possibilidade de "trajetória social ascendente" e o enfraquecimento da subordinação estrita e imediata. Isso seria uma contradição, dentro de uma perspectiva de um Estado autoritário. Suas ações, portanto, deveriam evitar que a fronteira passasse a representar um perigo, daí a necessidade de ser controlada.

Além dessa perspectiva apresentada para compreender a fronteira dentro de um contexto autoritário, Velho ainda aponta uma forma de pensar a fronteira que extrapola a temporalidade do regime autoritário e a Amazônia. Segundo ele, fronteiras podem ser criadas ou fechadas. "É como se fosse criado um equivalente a uma fronteira: assim como uma fronteira física pode ser fechada por meios sociais, uma espécie de 'fronteira' pode aparecer onde antes não havia nenhuma, devido a eventos sociais" (Velho, 1979, p.101).

Isso nos permite inquirir se a fronteira amazônica é a criação de uma fronteira a partir de resultados de eventos políticos e de trajetórias, que realizaram a criação de uma fronteira onde não havia nenhuma.

Ele continua. 
Isso nos ajuda a desmistificar a Fronteira como tal. De certa maneira não é simplesmente a fronteira que produz os efeitos que apontamos, mas algo que ela "contém" e que, como sugerimos no primeiro capítulo, pode apresentar-se com uma "face" diferente alhures. E ainda mais, isso mostra algo extremamente importante do ponto de vista político que é o fato de o acionar desse elemento poder não se dever exclusivamente a razões "sociológicas" dadas, mas sim também à própria ação política (do campesinato, de um partido, etc.), ela mesma alterando o curso da trajetória social. (ibidem, p.101)

Apesar de não tratá-la como um fato preestabelecido, o que nos permite pensá-la enquanto construção teórica, ele afirma que a fronteira “contém” algo, o que implica entendê-la como um fenômeno que pode ser descrito a partir suas características intrínsecas de uma fronteira. Essa tentativa de descrever e caracterizar a fronteira também foi feita por outros pesquisadores.

\section{Amazônia dos brabos e dos caboclos}

João Pacheco de Oliveira Filho (1979) se apropriou das discussões acerca do tema fronteira e estabeleceu um estudo acerca do assunto. Ele buscou estabelecer caracterizar a fronteira, formulando, para isso oito teses.

Em sua primeira tese afirmava:

Em primeiro lugar, fronteira não é um objeto empírico real, uma região, ou ainda, uma fase na vida de uma região, mas sim uma forma de propor uma investigação. A listagem habitual das áreas de fronteira não significa, portanto, uma enumeração de referentes concretos subsumidos no conceito de fronteira, mas tão-somente a indicação de objetos empíricos aos quais a aplicação de uma análise em termos de fronteira pode ser altamente rentável do pondo de vista da aplicação do conhecimento. (Oliveira Filho, 1979, p.111)

Nessa sua primeira definição, podemos observar que o autor define a fronteira como elemento conceitual, não empírico. Enquanto conceito é construção, logo, um feito, não um dado. Ela é resultado, e não proposição. Todavia, é da forma empírica que vem sendo tratada historicamente nas políticas do Estado brasileiro.

O enraizamento de um pensamento que identifica um lugar, que possa ser encarado como um marco divisório, não é recente no Brasil. Antes mesmo da década de 1950, Oliveira Vianna buscava compreender e propor soluções para aquilo que ele chamava de $O$ problema da unidade nacional. Vianna compreendia que um país da dimensão do nosso, para compor, efetivamente, uma unidade territorial e, em consequência, uma identidade nacional precisava superar os empecilhos produzidos pela distância, geradores das diferenças. Para ele somente um efetivo sistema de transportes seria capaz de integrar os arquipélagos que formavam o Brasil.

Durante os anos 1950, essa discussão esteve sob influência do pensamento cepalino. A tentativa de equacionar os problemas nacionais colocava na ordem do dia a questão regional e as fronteiras internas. Enxergava-se um país com realidades distintas: um Brasil moderno e outro arcaico. Essa construção dualista 
reproduzia-se enquanto elemento explicador para as ilhas brasileiras, ganhando peso a ideia dos Dois Brasis. As discussões não se esgotavam por aí, pois, se no plano internacional, a deterioração das relações de troca eram encaradas como o elemento que estava na base do colonialismo, a tendência seria reproduzir numa escala interna essa mesma "disfunção". De acordo com Celso Furtado (1979), a dualidade econômica e o rompimento da economia de arquipélagos tenderiam a reproduzir essa disparidade. Caberia, portanto, ao Estado brasileiro evitar que reproduzíssemos internamente o mesmo mal que afligia as relações internacionais de troca. O Estado deveria assumir um papel redistributivista para resolver esse problema.

Durante o período militar a ação do Estado sobre a região tinha como elemento discursivo central a política de integração, desenvolvimento e colonização. O que podemos notar ao longo desse período é a preponderância da ideia de fronteira estabelecida por Oliveira Vianna. A ideia de outro Brasil e de uma unidade nacional enquanto equacionadora dos problemas brasileiros foi a tônica das ações do Estado. Ou seja, o Estado definiu, com base em elementos empíricos, que a Amazônia era uma fronteira aberta para compor a unidade nacional e palco de políticas de integração. Devemos ressaltar, como faz Oliveira Filho, que a fronteira amazônica não existe a priori. Ela é resultado de uma construção histórica, que tinha na base a ideia de fronteira e no discurso colonizador a necessidade de se construir a unidade e a homogeneização. A primeira tese de Pacheco Filho, em certa medida, a necessidade de repensar conceitualmente a fronteira, caso contrário correríamos o risco de reproduzir as práticas históricas do Estado brasileiro.

Em sua segunda tese, o autor afirmava:

Segundo, a análise em termos de fronteira não inclui uma simples contextualização de uma área dentro de uma unidade (econômica ou política) de nível superior. Na verdade o modelo teórico da fronteira supõe uma totalidade composta por partes heterogêneas e com diferentes ritmos de funcionamento. A fronteira é então o estabelecimento de um mecanismo que correlacione de forma regular e complementar diferentes partes de uma totalidade (que tanto pode ser intranacional quanto associar partes pertencentes a diferentes países). $\mathrm{O}$ vínculo anteriormente referido entre a Amazônia e o Centro-Norte constitui um bom exemplo dessa complementariedade. (Oliveira Filho, 1979, p. 111)

Para ele, as bases para podermos pensar a fronteira são a totalidade e a heterogeneidade. Somente a possibilidade de encarar uma região ou uma área enquanto parte de um todo é que possibilita construir a ideia de fronteira, baseando-se na diferença. A pergunta que não está presente é "quem é fronteira para quem?". Se há heterogeneidades que fazem parte de uma mesma totalidade, somente no campo da disputa é que se poderá determinar qual área é a fronteira.

Francisco de Oliveira (1977) afirmava que não há como entender a região isolando-a na sua peculiaridade. Não há como percebê-la enquanto arquipélago. Se, como afirmava Milton Santos, "produzir é produzir espaço", a produção de 
uma região ou de uma fronteira não pode ser entendida sem a compreensão da organização socioeconômica da sociedade e das forças que estão em disputa. Corroborando a afirmativa de Francisco de Oliveira, nosso autor chama-nos atenção para as diversas relações de força existentes e atuantes na totalidade definida na tese anterior.

Na sua terceira tese, ele nos afirma:

Terceiro, as partes que compõem essa totalidade não podem ser concebidas enquanto modelos universais e genéricos, que enfoquem a realidade por um prisma à exclusão de outros (o econômico, p. ex., à exclusão do político e do ideológico). Assim é inadequado pensar tais unidades em termos de modos de produção ou de sistemas econômicos, políticos, etc. A análise dos modos de produção encontradas em escala local precisa dar conta da particular articulação existente entre eles e paralelamente inclui realidades políticas e ideológicas sem as quais não poderia ocorrer a reprodução econômica e social daquela sociedade (Oliveira Filho, 1979, p. 111)

Essa terceira tese indica que para compreender o fenômeno da fronteira não devemos isolar a compreensão da totalidade apenas por um viés. Ao incorporá-la na complexidade existente nas formações sociais locais, pertencentes à totalidade, o autor acentuou o fato de que dinâmicas heterogêneas devem ser compreendidas na sua articulação com o todo.

Foi o isolamento de determinadas classificações genéricas a base para caracterizar a Amazônia e atuar sobre a fronteira. Excluíam-se, dessa forma, outras possibilidades para se compreender a região. Os planos de desenvolvimento econômico para a integração nacional produzidos a partir do Centro-Sul do país, ou como nos afirmou Ariovaldo Umbelino, a partir de interesses internacionais, trataram a questão da fronteira unicamente a partir do viés econômico, à exclusão de outros. O resultado disso foi percebido durante os anos 1980, quando a questão ambiental entrava em cena. Todavia, a atualidade dessa tese reside nas leituras, sobretudo aquelas baseadas nas preocupações ambientais, que hoje produzem propostas de intervenção na região. $\mathrm{O}$ mesmo defeito de origem se perpetua, ou seja, a análise tem suas cores baseadas em uma perspectiva ecológica, não inserindo esse viés no todo. Não a incorpora na complexidade do cenário.

As perspectivas de intervenção, tanto as que pensaram o desenvolvimento ou as mais recentes, que interpõem o viés ecológico, basearam-se numa espécie de "vocação" natural ou empírica para fundamentar a atuação sobre a Amazônia. Num primeiro momento eram as terras livres, férteis, lugar desabitado e de natureza pujante, devendo ser integrado. Num segundo momento é o locus da biodiversidade, a maior reserva de água potável do planeta etc. Esse olhar que naturaliza a região é também questionado na quarta tese do autor.

Quarto, é preciso desautorizar a crença de que as partes que compõe essa totalidade estejam dotadas naturalmente de características complementares: a abundância de terras livres e a superpopulação não constituem fatos concretos e inexoravelmente referidos a uma região, mas são traços que podem ser ge- 
rados ou alterados a partir de uma intervenção sobre outros elementos dessas realidades. (Oliveira Filho, 1979, p. 111)

Na sua quarta tese, exposta acima, Oliveira Filho nos permite relacioná-la à ideia de produção histórica dos elementos empíricos do conceito e de sua posterior naturalização. A caracterização e a classificação de uma dada região é uma representação construída a partir de um lugar social, logo, de uma dada visão-intervenção no mundo. É resultante de um poder simbólico, associado a uma violência simbólica observada na produção da demarcação.

Ainda em sua quarta tese, afirma:

Essa complementaridade natural entre regiões está suposta na definição de colonização como “ocupação de terras novas", sendo um componente ideológico fundamental o mito da fronteira aberta. Deixando de lado a sua eficácia ideológica, o desenvolvimento de tais colônias de povoamento coloca para os economistas uma questão mais básica: a de como importar as relações de produção necessárias ao funcionamento do capitalismo na colônia. (Oliveira Filho, 1979, p. 111)

Ao tratar da fronteia como terras novas ou terras livres, estamos diante de uma construção que o autor chama de ideológica. Podemos, da mesma maneira, perceber que enquanto área a ser preservada, a Amazônia é resultante de um processo idêntico.

Nas teses finais sobre fronteira, que falam de fronteiras capitalistas, o conceito ganhou um aporte temporal historicamente situado.

$\mathrm{Na}$ quinta tese, o autor argumentou que era necessário que uma das partes da totalidade tivesse mão de obra excessiva, ante os recursos de subsistência gerados pelas mais diferentes motivações. Segundo ele, é a extinção do pequeno produtor que é capaz de explicar movimentos de colonização e não simples políticas do Estado para dirigir o processo migratório. Ao relacionarmos essa quinta tese com a argumentação anterior, perceberemos que as "diferentes motivações" têm origem no campo econômico e/ou político. Portanto, extinguir o pequeno produtor e lançá-lo como mão de obra não autônoma é um processo inerente do capitalismo (inclusão forçada). Conjuntamente a isso, verificamos na migração dessa mão de obra (seja dirigida ou voluntária), para áreas denominadas como fronteiras, uma nova dinâmica desse modelo dominante, a exclusão (Fontes, 1997).

Na sexta tese, o autor argumentou que na fronteira deveriam ser criados mecanismos de controle sobre a mão de obra, ao contrário da ideia de igualitarismo existente nessas regiões, o que nos leva a crer que, mais do que a denominação da fronteira, surgiam, concomitantemente, outras duas características: 1) a área a ser incorporada deveria reproduzir as mesmas relações de produção da área dominante; 2) a fronteira, ao ser estabelecida enquanto tal, traz no seu código genético sua identidade, forjada a partir da visão de mundo de seu criador.

A sétima tese, decorrente da sexta, supõe uma reorganização do mundo social da fronteira sob novas bases, geradas na representação do modelo dominante e voltadas para ele. 
A oitava tese, amarrando as partes, determinou que não bastaria a reorganização, mas seria preciso, também, construir os agentes e as atividades que as ligariam com a totalidade.

A temporalidade existente nas últimas teses insere a fronteira na dinâmica capitalista e a ação dessa dinâmica sobre a fronteira, o que não deve ser deixado de lado. Todavia, as quatro teses nos servem para pensar a ação sobre a fronteira, isto é, uma área caracterizada como fronteira.

Da mesma forma que Oliveira Filho, o grupo de Bertha Becker se destacou nessa temática, produzindo teses explicativas para a ação do Estado na fronteira amazônica.

\section{Classificando a fronteira}

Bertha Becker (Becker et al., 1990), em seu grupo de pesquisas na Universidade Federal do Rio de Janeiro, elaborou, durante os anos 1980, diversos estudos acerca da colonização e da fronteira na Amazônia. Nas análises sobre a ocupação do espaço amazônico e das dinâmicas que a alteraram, e ainda a alteram, o cenário da região, Bertha Becker buscou elaborar uma teorização referente à fronteira. Ela enumerou oito teses sobre o tema que, segundo ela, fugiam das elaborações baseadas nas disputas ideológicas, que marcaram grande parte das interpretações surgidas nas décadas de 1970 e 1980.

Em sua primeira tese, ela afirmou:

Parte integrante da sociedade nacional, participando do modelo de crescimento tecnológico intensivo de capital com intensa mediação do Estado, a fronteira tem como especificidade o fato de ser espaço não plenamente estruturado. (Becker et al., 1995, p. 15)

A autora afirmou, em considerações posteriores baseando-se na tese de Otávio Guilherme Velho, que a fronteira é "espaço não estruturado". Não significa dizer que não haja estruturação no espaço da fronteira, mas que a estruturação existente não está de acordo com o que se considera e se afirma no Estado, enquanto estruturação dominante. Portanto, não há como considerá-la independentemente da posição que o Brasil ocupa no cenário mundial, como também não há como considerá-la sem compreender o lugar que ocupa a Amazônia no espaço político-econômico brasileiro.

A expansão da fronteira amazônica só pode, portanto, ser compreendida a partir da inserção do Brasil, neste final do século XX, no sistema capitalista global articulado aos interesses do capital industrial e financeiro, com a mediação do Estado. (ibidem, p.16)

Citando Lefebvre, salientou que a ação do Estado não poderia ser considerada apenas reflexo de interesses econômicos enraizados em seu interior. Ressaltou, ainda, que o Estado, ao construir-se enquanto mediador de interesses de classe acabaria por circunscrever o processo de modernização. A partir disso, impõe ao espaço existente uma nova espacialização:

O Estado coordena a nova divisão inter-regional do trabalho. Ele reorganiza 
o caos das relações sociais impondo-lhes uma racionalidade - a sua - tendo como instrumento privilegiado o espaço: o econômico se reconsidera em termos espaciais - fluxos e estoques - e o Estado tende a controlá-lo, a assegurar sua coordenação, integrando e rompendo o espaço anterior, e produzindo seu próprio espaço. (ibidem, p.16)

Mais adiante afirmou, ainda em sua primeira tese, que a fronteira influi no espaço global, na medida em que representa um espaço de manobras, e a sua permanência enquanto espaço alternativo é um elemento ideológico cultivado para ações futuras do Estado. Nessa formulação, Becker trata o Estado e a fronteira da mesma maneira: como um ente.

Em sua segunda tese, nos diz: “A apropriação da terra realizada em escala e ritmo crescentes, contudo, não é total nem uniforme nem irreversível: a fronteira não está fechada" (ibidem, p.17).

Nessa tese ela aponta para formas variadas de apropriação de terras. Segundo ela, o Estado criaria condições de proporcionar a apropriação privada, para setores que detêm capital e condições de investimento, como proporcionaria o acesso à terra a segmentos sociais que não possuem tais características, produzindo, assim, um efeito político reformista. Essa margem de manobra aponta para uma fronteira aberta, possuidora de virtualidades políticas a serem utilizadas pelo Estado, de acordo com as mudanças de conjuntura, no que concorda com Velho.

Em sua terceira tese a autora afirmou: "A mobilidade da força de trabalho tem sido condição de constituição da fronteira e a migração não é um processo dominantemente espontâneo" (ibidem, p.19).

A mobilidade da mão de obra, segundo ela, é requisito fundamental para o Estado controlar as ações sobre a fronteira. A existência de mão de obra em escassez na fronteira é um elemento atrativo para as ações das colonizações oficiais ou privadas. A utilização de mão de obra sazonal implica a necessidade de deslocamento de trabalhadores, através de um fluxo urbano-rural nas fronteiras. Para tanto, há necessidade de mão de obra não qualificada, como propugnava a legislação que priorizava a utilização de mão de obra nordestina. Ela nos chama a atenção para esse movimento, ocorrido no Brasil.

$\mathrm{Na}$ quarta tese, baseada nas afirmações anteriores, ela diz: “O processo de diferenciação do campesinato tem sido condição de extensão da fronteira” (ibidem, p.20).

Ao falar da diferenciação do campesinato, Becker salientou que a tendência apontada no item anterior poderia obedecer a critérios outros, que não apenas econômicos. Alertou para uma diferenciação do campesinato, que poderia estar baseada em elementos culturais. Porém, a expansão do capital acabaria por “testá-los", no sentido de conseguir produzir uma acumulação ampliada. Ela afirma:

Trata-se, nesse caso, da reprodução direta da pequena produção do sul, re- 
produção não só da população como da modalidade de sua subordinação ao capital comercial, e hoje também ao complexo agroindustrial. Resta ver se conseguirão uma reprodução ampliada. De qualquer modo, fato fundamental a registrar é que o grupo camponês não é um bloco monolítico e não funciona mais segundo um projeto único, mas segundo estratégias diferentes e que até se opõem. (ibidem, p.21)

A quinta tese nos diz: "A expansão da fronteira efetua-se num contexto urbano, condição de organização do mercado de trabalho regional e de ocupação do território" (ibidem, p.21).

Aqui temos um dado considerado secundário ao tratar-se de fronteira. A criação de núcleos urbanos funcionaria como elemento fundamental para a circulação de mão de obra e de mercadorias. Seria uma forma de sugerir uma reprodução do modelo dominante, criando núcleos urbanos semelhantes aos polos dominantes da economia globalizada. Ela diz:

Daí verificar-se, na fronteira, a urbanização em suas múltiplas formas, desde o crescimento explosivo de cidades velhas e novas à multiplicação de núcleos e povoados fortemente instáveis. Processo de urbanização "espontâneo" e, nos anos 1970, explicitamente dirigido, seja através do urbanismo rural (INCRA) que a considerou necessária para atrair a população, por oferecer condições de vida similares às áreas dos migrantes, seja através do Polamazônia. O núcleo urbano tem papel fundamental na ordenação do território como sustentáculo da circulação da força de trabalho, do capital e da informação, como mediador da ação político-ideológica do Estado, e, limitadamente, exerce ele papel gerativo na região. (ibidem, p.21 e 22)

O caso de Porto Velho é singular nesse sentido, pois o crescimento populacional teve forte impulso, a partir dos programas de colonização, o que também verificamos no restante do Estado, o que fica evidenciado pelos censos populacionais do IBGE. Hoje, em Rondônia, os núcleos urbanos situados ao longo do eixo da rodovia BR 364 apresentam, juntamente com a capital, as maiores concentrações populacionais do Estado, situando-se entre os primeiros os municípios de Ji-Paraná, Ariquemes, Cacoal, Jaru e Vilhena, segundo o Censo de 2000.

Em sua sexta tese a autora argumenta sobre a homogeneização e a diferenciação das áreas incorporadas ao espaço global. A incorporação da fronteira obedeceu, durante o período militar, à égide do discurso da integração nacional. “A rápida reestruturação do espaço regional é fruto e condição da integração do território nacional" (ibidem, p.23).

Nessa tese nos é salientada a necessidade de não perceber a área incorporada de acordo com o discurso que a formula. A construção de uma "integração nacional", como discurso de homogeneização do desenvolvimento, não nos deixa perceber as sutilezas das relações que subjazem tal discurso. A possibilidade de perceber as diferenças está nos diversos níveis de articulação/participação da iniciativa privada nas diversas modalidades de ocupação da fronteira amazônica. Ao passo que temos a presença privada mais visível na região meridional da 
Amazônia Legal, observamos a presença mais marcante dos projetos oficiais de colonização ao longo da Transamazônica.

A sétima tese diz respeito aos efeitos da ação controladora do Estado e da forma como gerencia as apropriações/desapropriações e o acesso à terra. "Os conflitos que ocorrem na fronteira são intrínsecos à sociedade brasileira e constituem fruto e condição da integração do território" (ibidem, p.24).

A forma pela qual o Estado brasileiro, durante o período militar, reordenou o território da fronteira gerou conflitos diversos: nos núcleos urbanos, com populações tradicionais, com o campesinato residente etc. Outros conflitos, salientados pela autora, não são exclusivos das regiões de fronteira, mas típicos de uma sociedade capitalista, pois dizem respeito às lutas da força de trabalho proletarizada. Com a tendência à homogeneização, eles passam a ocorrer na fronteira.

Em sua última tese, Bertha Becker nos diz: "As alternativas em discussão mobilização e mobilidade - são complexas e contraditórias" (Becker et al., 1990, p.25).

Essa tese é política e nos aponta para o "depois". A autora deixa de tratar de uma conceituação sobre fronteira, para fazer uma predição de cunho político. Ela afirma que é preciso compreender a fronteira não apenas como um locus de expansão do Estado, pois as discussões em torno da mobilidade da mão de obra têm se deslocado para a mobilização, sem, entretanto, compreender as vicissitudes dessa configuração espacial tão própria. Ela argumenta que:

Novas questões se colocam, então, para a compreensão da complexidade da fronteira. A intensidade dos processos migratórios atuais e o peso das cidades parecem indicar que a reforma agrária seja condição necessária, mas não suficiente para solucionar a complexa teia de problemas ali existentes. É preciso buscar também soluções tipicamente urbanas, através da organização plena do mercado de trabalho, que permitam a conquista da cidadania. (ibidem, p.25)

A despeito de contribuir para construir uma conceituação para pensar a fronteira, as teses da autora apontam para a compreensão dos fenômenos da fronteira amazônica circunscrita nas décadas de 1970 e 1980, perdendo, em grande parte, a possibilidade de reatualização e reutilização do conceito. Em um caminho diverso, José de Souza Martins abre outras possibilidades de pensar a fronteira.

\section{Fronteira, mais do que um lugar, uma temporalidade}

José de Souza Martins (1997), num emocionante livro acerca da fronteira, nos presenteia com uma leitura diferenciada. Sua trajetória de pesquisa se pautou por uma opção metodológica que o levou a atravessar áreas de conflito, vivenciá-los, apaixonar-se por seu objeto, ter paciência com o método e com o tempo e, por fim, o resultado foi uma produção baseada na vivência do conflito nas regiões de fronteira.

Em viagens realizadas pela região da Amazônia Legal, buscando compreender os efeitos do processo de ocupação resultantes dos múltiplos programas 
de integração na região, o autor encontrou na convivência com camponeses e indígenas respostas muito diferentes para o tema de sua pesquisa, pois para essas populações, o nós ainda não havia se configurado. Aquele que se apresenta e não é um chegante, como Martins nos relata, é apenas um passante, ainda é o outro. A opção da pesquisa priorizou a compreensão desse outro, que não se considera nós. Ou, como nos diz Martins, sua opção de análise foi procurar estabelecer uma convivência com as vítimas da expansão da fronteira, notadamente indígenas e camponeses.

É na condição de vítima que podem ser encontradas duas características essenciais da constituição do humano, suas fragilidades e dificuldades, numa sociabilidade que parece nova, aparentemente destituída dos automatismos da reprodução social, característicos das regiões de ocupação antiga. Refiro-me a alteridade e à particular visibilidade do Outro, daquele que ainda não se confunda conosco e nem é reconhecido pelos diferentes grupos sociais como constitutivo do Nós. (Martins, 1997, p.12)

Essa metodologia levou-o a forjar uma teoria acerca da fronteira, que o diferencia dos autores mencionados anteriormente.

A fronteira é, sobretudo, no que se refere aos diferentes grupos dos chamados civilizados que se situam "do lado de cá”, um cenário de intolerância, ambição e morte. [...] Já no âmbito dos diversos grupos étnicos que estão "do outro lado", e no âmbito das respectivas concepções do espaço e do homem, a fronteira é, na verdade, ponto limite de territórios que se redefinem continuamente, disputados de diferentes modos por diferentes grupos humanos. (ibidem, p.10 e 11 )

Para ele, a fronteira não é um lugar dado, mas uma criação, cujo resultado fica estampado nos inúmeros conflitos que a constituem. “... A fronteira de modo algum se reduz e se resume à fronteira geográfica. Ela é fronteira de muitas e diferentes coisas: fronteira espacial, fronteira de culturas e visões de mundo, fronteira de etnias, fronteira da História e da historicidade do homem. E, sobretudo, fronteira do bumano" (ibidem, p.13).

Essa relação se torna, assim, uma relação de força entre diferentes. O resultado desse conflito (ou mesmo da denominação da fronteira) é a identificação a alteridade. Ao subjugar, domina. Ao explorar, é explorada. Ao viver, morre. A fronteira possui esse caráter litúrgico e sacrificial. A imposição de um novo modus vivendi implica no sacrifício de outro.

No caso específico da fronteira amazônica, não há como desatrelar sua ocupação do processo de expansão do capital, seja na área de mineração, como afirma Ariovaldo Umbelino, seja por conta da mudança da estrutura agrária no centro-sul do país, como nos falou Francisco de Oliveira (1977). A imposição de um modus vivendi sobre outro implica reconhecer a heterogeneidade dentro de algo que é reconhecido como parte de uma mesma totalidade, como nos lembra João Pacheco.

Não perdendo de vista a totalidade, Martins afirmava que não se produz 
na fronteira algo propriamente novo, mas o choque entre formações sociais distintas. $\mathrm{O}$ resultado desse choque tem como beneficiário o que denomina o outro enquanto outro, ou seja, a parcela dominante dessa relação.

O aparentemente novo da fronteira é, na verdade, expressão de uma complicada combinação de tempos históricos em processos sociais que recriam formas arcaicas de dominação e formas arcaicas de reprodução ampliada do capital, inclusive a escravidão, bases da violência que a caracteriza. As formas arcaicas ganham vida e consistência por meio de cenários de modernização e, concretamente, pela forma dominante da acumulação capitalista, racional e moderna. (ibidem, p.5)

Ao afirmar que a "fronteira é essencialmente o lugar da alteridade", Martins (1997, p.150) não se limitou a pensar em papéis distintos na sociedade presentes na fronteira: o civilizado versus o bárbaro; o branco versus o indígena; o latifundiário versus o camponês. A alteridade que nos chama atenção é a dos tempos distintos presentes na fronteira. Ele afirma: "O desencontro na fronteira é o desencontro de temporalidades históricas, pois cada um desses grupos está situado diversamente no tempo da História" (ibidem, p.151).

Mais do que diferenças culturais, a noção de temporalidade histórica distinta indica um padrão de relações sociais e do homem com o meio, também, distintos. Mas a incorporação do outro ao nós, através de um processo onde a violência, seja ela simbólica ou física, é parte crucial, tende a diminuir as distâncias temporais. A fronteira só deixa de ser criada e recriada enquanto fronteira, ou inventada aonde não existia (como diria Velho), na medida em que o outro se torne nós. Nesse sentido, a reflexão de Martins colabora com a nossa formulação.

A fronteira só deixa de existir quando o conflito desaparece, quando os tempos se fundem, quando a alteridade original e mortal dá lugar à alteridade política, quando o outro se torna a parte antagônica do nós. Quando a História passa a ser a nossa História, a História dessa diversidade e pluralidade, e nós já não somos nós mesmos porque somos antropofagicamente nós e o outro que devoramos e nos devorou. (ibidem, p.151)

Martins nos faz indagar: qual é o lugar da Amazônia na História do Brasil hoje? A Amazônia já se sente como um “nós” ou ainda continua sendo um “outro"? Que temporalidades atravessam essa relação?

Para responder a essa pergunta buscamos um elemento surgido na década de 1970 e que avançou no Brasil nos anos 1980: o discurso da sustentabilidade. Ao incorporar esse elemento na avaliação das temporalidades da fronteira, teríamos, então, duas outras temporalidades presentes na Amazônia de hoje: a temporalidade das populações tradicionais, a temporalidade do desenvolvimento e a temporalidade da sustentabilidade. Mas em que medida isso significa recriar novas fronteiras?

\section{Ecologismo: crise do modelo de desenvolvimento?}

O que fazer com o desenvolvimento local ou para o local, que tanto problema ambiental produziu? Aonde inserir a retórica da sustentabilidade ou do 
ecologismo? Como desenvolver preservando o ambiente? Serão esses dois elementos (Desenvolvimento e Sustentabilidade) antagônicos? A resposta à última questão me parece afirmativa, sendo assim, as perguntas anteriores perderiam o sentido.

O que se consolidou sobre a ideia de desenvolvimento está historicamente amalgamado ao indicador crescimento econômico. O paradigma de uma sociedade desenvolvida, tal como afirmava Rostow (1971), é uma sociedade de consumo de massa. A crescente produção de mercadorias nos conduziu e ainda conduz para um consumo também crescente. Essa análise feita sobre o capitalismo já era apontada por Rosa Luxemburg ao analisar a acumulação capitalista, todavia, a partir de um ponto de vista crítico ao sistema. Segundo Luxemburg (1985, p.228): "Já que a produção capitalista é consumidora exclusiva do próprio mais-produto, não há nenhum limite para a acumulação capitalista".

Esse modelo de desenvolvimento sofreu fortes pressões ambientalistas no final dos anos 1960. O Clube de Roma alertava para os limites do crescimento, afirmando que o planeta não teria recursos naturais para atender às crescentes demandas produtivas. Tais preocupações foram objeto de discussão na Conferência das Nações Unidas em 1972 (Estocolmo), onde era apontado que um dos causadores dos problemas ambientais era a miséria e a falta de uso de tecnologias adequadas no terceiro mundo. Como produto dessas discussões, um novo modelo de desenvolvimento foi forjado pelo Relatório Brundtland, o Desenvolvimento Sustentável. Retirava-se do centro da discussão os rumos da produção capitalista de mercadorias e qualquer referência ao nome capitalismo.

A luta ecológica, que surgiu como crítica à sociedade de consumo, passou a fazer parte dessa. O mundo do pós-guerra era o mundo do fracasso da humanidade. A sociedade ocidental produziu guerras que mataram milhões de pessoas. Produziu uma bomba capaz de aniquilar cidades inteiras. Produziu o genocídio, a violência e a possibilidade de destruição do planeta, seja por poderio bélico, seja por atividade industrial. A ameaça ao meio ambiente passava a fazer parte do discurso que questionava a sociedade ocidental e seus valores. $\mathrm{O}$ Ecologismo foi engolido e adequado para não se mexer no processo produtivo. O Desenvolvimento Sustentável era a resposta para continuar produzindo e salvar o planeta, ao menos em teoria.

\section{O conceito enquanto crise}

Mais do que um novo paradigma, esse conceito emergiu de uma crise. As manifestações pacifistas e ambientalistas dos anos 1960, que contribuíram para incorporar no sentido de desenvolvimento a ideia de desenvolvimento limpo, legaram para nós duas temporalidades.

A primeira temporalidade diz respeito ao mundo que se abominava, pois produzira guerras, bombas atômicas, holocausto, miséria, fome e destruição da natureza. $\mathrm{O}$ mundo industrial que não servia não foi retirado de cena, como tampouco a ideia de desenvolvimento que o fazia mover. Ao atrelar o con- 
ceito de desenvolvimento ao de progresso e crescimento econômico, tinha-se como pressuposto para o desenvolvimento a mesma lógica do capital, ou seja, a de uma acumulação ampliada, que incorpora continuamente novos espaços ou novas tecnologias. Desenvolvimento, então, faz parte de uma temporalidade e racionalidade moderna.

A outra temporalidade diz respeito ao termo sustentável. Surgido enquanto alarme para os rumos do crescimento, ou mesmo negação de um modo de vida consumista. A defesa do meio ambiente e seu corolário, a ideia de sustentabilidade, são marcos de um pensamento que produziu lutas localizadas, descrente da possibilidade de uma teoria holística do social. Temos então um choque entre temporalidades numa mesma equação: Desenvolvimento (moderno) e Sustentável (pós-moderno).

Qual a implicação disso para a compreensão, ou mesmo execução, de políticas baseadas nesse princípio, que já nasce em crise? A contínua impossibilidade de praticá-lo em escala macroeconômica, como já nos alertava Bertha Becker (1995, p.54). "Coloca-se, assim, em questão o conceito de desenvolvimento sustentável baseado em práticas de pequena escala, que não parecem capazes de potenciar o desenvolvimento regional nem presente nem futuro".

O resultado disso são soluções políticas também contraditórias. Se retomarmos o projeto "Avança Brasil”, observaremos que ao mesmo tempo que se determinava a imperativa necessidade de controlar o avanço sobre a Amazônia e a sua devastação, o programa apontava para a também imperativa necessidade de investimentos que são acusados de causar degradação. Convém lembrar que ambas iniciativas recebiam o significativo nome de Desenvolvimento Sustentável, denominado por Bertha Becker como uma verdadeira caixa-preta. O conflito é inerente à História, entretanto a contradição estava na gênese do conceito de Desenvolvimento Sustentável e continua nas tentativas para a sua aplicabilidade através de políticas de Estado. Vejamos.

\section{Amazônia uma nova fronteira para a luta ambientalista}

Uma das alterações produzidas recentemente, causada pela incorporação do elemento ambiental no discurso do desenvolvimento, foi o estabelecimento de novas diretrizes para o uso da terra. A Amazônia, um dos principais objetos de preocupação dos ambientalistas, voltou à cena e tornou-se objeto de disputa pela sua significação.

O crescimento da produção de soja no cerrado brasileiro e a sua importância macroeconômica na balança comercial produziram mudanças no cenário da Amazônia Meridional. Podemos citar três alterações significativas: 1) a penetração do plantio de soja na Amazônia Meridional; 2) a demanda pela construção de rodovias para o escoamento da produção e; 3) a efetivação da hidrovia Madeira-Amazonas. Os três empreendimentos são caríssimos para os defensores do desenvolvimento, ao passo que significam um retrocesso para os defensores da floresta. 
Outros instrumentos para o desenvolvimento da região têm sido objeto de disputas entre elementos da sociedade civil (via as $\mathrm{ONG}$ ), que defendem o meio ambiente, os indígenas e populações tradicionais (ribeirinhos e seringueiros) e os defensores de desenvolvimento econômico local (madeireiras, pecuaristas, agricultores etc.). A construção das hidrelétricas do Rio Madeira é apontada por esses últimos como investimento necessário para o desenvolvimento regional. O ponto de vista defendido por grupos ambientalistas entra em conflito com as demandas para o desenvolvimento, pois o investimento produzirá impactos profundos na floresta e no modo de vida de populações do entorno.

Nesse sentido, temos o cenário desenvolvimentista, que significa o avanço sobre a antiga fronteira agrícola, e temos o cenário ambientalista, que ao defender a floresta e seus povos propõe a construção de uma nova fronteira, mas em sentido inverso.

\section{A fronteira volátil}

Em uma rápida consulta aos dicionários de sinônimos, como também dicionários de Ciências Sociais, o verbete fronteira aparece relacionado aos limites entre um Estado e outro, ganhando relevância, principalmente, durante o período das formações das monarquias nacionais, quando o estabelecimento dos marcos de alcance do poder do Estado necessitava de maior precisão. Nessa época, a demarcação da fronteira buscava na geografia os elementos necessários para defini-la com rigor. Contudo, o verbete fronteira alçou voos que vão além de um dicionário de sinônimos e dos limites impostos por acidentes geográficos. O verbete tornou-se um conceito que, ao tratar de fronteiras internas e/ou incertas, teve como objetivo elucidar mais do que um simples limes. O conceito ganhou ao longo do tempo adjetivos e significações diferenciadas: fronteira aberta, fronteira fechada, fronteira incerta, fronteira controlada etc. Todas essas ressignificações têm por característica comum, independentemente de quem as tenha formulado, alterar a visão anterior em pelo menos um aspecto: a fronteira não demarca simplesmente limite entre um Estado nacional e outro, demarca o limite entre um estado de coisas e outro; entre determinadas características (econômicas, sociais, políticas etc.) e outras; entre uma região e outra. Estabelecemos assim nossa primeira tese sobre a fronteira: A fronteira marca a diferença entre duas ou mais regiões. O lado de lá da fronteira é o lugar do diferente.

Mais do que simplesmente considerarmos a fronteira como um dado, devemos, portanto, considerá-la como um produto político. Ou seja, fruto de um processo histórico, que tem sua origem no campo do poder e/ou no campo intelectual. Vivemos tal produção da diferença durante o período militar, quando a questão regional e das fronteiras internas, bem como os desníveis entre o centro-desenvolvido e a periferia-dependente ganharam novos contornos. Tratava-se de viabilizar um desenvolvimento nacional hierarquizado, buscando fortalecer as trocas inter-regionais. A discussão das fronteiras internas fincava-se em um patamar apolitizado (Diniz Filho; Bessa, 1995). 
Aqui, a região é menos uma identidade buscada no confronto de forças sociais determinadas dentro de um campo de luta ideológica ricamente politizado, do que um espaço geográfico reificado pela tecnocracia estatal dentro das novas diretrizes impostas pelos órgãos de planejamento no país e na construção do "Brasil Potência”. (Diniz Filho; Bessa, 1995, p.32)

Os pressupostos, que marcaram a ação do Estado na fronteira nas décadas de 1970 e 1980 já estavam estabelecidos anteriormente. O que poderia ser apontado como um problema, na verdade não se constituiu em entrave, pois não havia como se pensar a fronteira para a expansão sem a referência a um contexto envolvente, a saber, a questão nacional, que era traduzida por Segurança Nacional e Integração Nacional.

Para que um conceito sobre fronteira possa se tornar efetivamente fecundo para o momento atual, observado como um conceito produzido no campo do poder e/ou intelectual, devemos deixar de ver a fronteira simplesmente a partir do seu produto, devendo buscá-la no produtor. Ou seja, os teóricos buscam identificar as distinções empíricas entre os dois lados da fronteira, quando, primeiramente, deveríamos perguntar: quem opera tal distinção? Pois, quem diz algo, o diz de algum lugar (econômico, político, cultural etc.), possuindo capital simbólico para tanto. Logo, ao concebermos tal conceito a partir de sua produção histórica, situada em algum lugar do campo do poder e/ou intelectual, chegamos à nossa segunda tese: a fronteira, ou melhor, a ideia de fronteira é antes de mais nada e apenas uma representação, na medida em que a existência física dela é também produto de construção simbólica.

Ao ser "recortada", a fronteira e os seus limites obedecem, supostamente, aos limites do meio físico, o que, por seu turno, é uma de suas formas de representação. No entanto, a fronteira, ao consolidar-se enquanto resultado de uma nomeação, que distingue o interior do exterior, cria e separa, ao mesmo tempo, identidades regionais diferentes. Distingue, em nosso caso, o "ser da fronteira" daquilo que não o é. Logo, mais do que uma simples descontinuidade física, a definição do limes conduz-nos, compulsória e simultaneamente, a diferenciações econômicas, políticas e culturais que a caracterizam enquanto diferente, homogeneizando em seu conjunto os elementos característicos de sua identidade regional. Roger Chartier (1990), ao refletir sobre o conceito de representação coletiva, considera que ela [a representação] nos leva para além das mentalidades, conduzindo-nos para formas visíveis de manifestação da representação:

Mais do que o conceito de mentalidade, ela [a representação] permite articular três modalidades da relação com o mundo social: em primeiro lugar, o trabalho de classificação e de delimitação que produz as configurações intelectuais múltiplas, através das quais a realidade é contraditoriamente construída pelos diferentes grupos; seguidamente, as práticas que visam fazer reconhecer uma identidade social, exibir uma maneira própria de estar no mundo, significar simbolicamente um estatuto e uma posição; por fim, as formas institucionalizadas e objetivadas graças às quais uns "representantes" (instâncias coletivas ou pessoas singulares) marcam de forma visível e perpetuada a existência do grupo, da classe ou da comunidade. (Chartier, 1990, p.23) 
Dessa forma, a região de fronteira, se entendida como uma representação histórica, situada no palco da disputa pela delimitação legítima, torna visível e perpetua a existência tanto do que nomeia (por ser portador de uma forma de poder) quanto do que é nomeado (por identificar-lhe a forma de estar no mundo). Essa modalidade de representação é fruto de um processo de poder e violência simbólica, fundamentada nos termos de Pierre Bourdieu (1989).

A representação, assim constituída, será mais eficaz quanto mais ignorada enquanto violência. $\mathrm{O}$ poder de enunciar será mais eficaz quanto mais ignorado como manifestação de poder. Dessa forma, podemos compreender as ações para o desenvolvimento (políticas de integração) e para a sustentabilidade (proposições com base no problema ambiental) com representações e como violência. Tanto o primeiro como o segundo construíram representações com o intuito de validar suas ações com base num processo de violência simbólica, construindo uma dada imagem de Amazônia e uma significação para a mesma, que justificavam a sua ação.

As políticas para o desenvolvimento inventaram o vazio demográfico, o risco para a segurança nacional, o eldorado, a necessidade de conhecer o território e suas riquezas, produzindo assim uma representação de fronteira. Já as políticas para a sustentabilidade inventaram o pulmão do mundo, a biodiversidade, o sequestro de carbono, o maior manancial de água potável do mundo, o que, em contrapartida, acabou por produzir uma nova representação para a mesma fronteira, o que implica, necessariamente, em construir a fala legítima e a consequente adoção de medidas para efetivar políticas públicas para a fronteira.

A enunciação dos limites fronteiriços tende, dependendo do capital simbólico de quem nomeia, a uma maior ou menor eficácia na construção da fala hegemônica. Entretanto, uma representação, formulada a partir de um determinado poder simbólico, sustentada pelo capital simbólico que acumulou, não se esgota em si. Uma representação tem um trajeto que não se inicia nela e nem se esgota no mesmo lugar. A representação para ser eficaz depende, sobretudo, da apropriação da enunciação como uma válida explicação de mundo (ignorada/ reconhecida) para que possa criar formas de estar no mundo. Poderíamos dizer de outra maneira: a representação, para concretizar seu ciclo, deve comandar atos e construir o mundo social (Chartier, 1990) A construção de representações, dentre elas a de fronteira ou regiões de fronteira, obedece à mesma lógica de produções simbólicas, que parece estar afastada do mundo social; no entanto, é formulada para a ação no mundo.

A localização das lutas pela delimitação legítima, portanto, só fará sentido se transpusermos o nível das trocas simbólicas, e alçarmos voos para a produção simbólica. A metodologia proposta por Chartier conduz-nos a caminhos a serem percorridos:

O primeiro diz respeito às classificações, divisões e delimitações que organizam a apreensão do mundo social como categorias fundamentais de percepção e de apreciação do real. Variáveis consoante as classes sociais ou os meios intelectuais, são produzidas pelas disposições estáveis e partilhadas, próprias do grupo. São 
estes esquemas intelectuais incorporados que criam as figuras graças às quais o presente pode adquirir sentido, o outro se tornar inteligível e o espaço ser decifrado.

As representações do mundo social assim construídas, embora aspirem à universalidade de um diagnóstico fundado na razão, são sempre determinadas pelos interesses de grupo que as forjam. Daí, para cada caso, o necessário relacionamento dos discursos proferidos com a posição de quem os utiliza. (Chartier, 1990, p.17)

Teríamos, então, na produção do conceito fronteira uma disputa de significados, que faz parte também do momento de produção. O resultado disso é que teríamos uma fronteira inventada a partir do embate entre os diversos agentes com capital simbólico suficiente para lutar pelo seu "consumidor" e pelo seu produto. Logo, a produção do conceito e da ação necessária sobre a fronteira é capaz de fundamentar as razões para a efetivação de políticas públicas. Um exemplo disso pode ser dado quando se consolidou a ideia de que a Amazônia era um vazio demográfico, logo, área apta a receber migrantes e necessitando de integração. Uma terra sem homens para homens sem terra, como propagandeava o slogan.

Mas, se quem fala algo o faz de algum lugar social determinado, devemos lembrar que as falas sobre a fronteira não foram produzidas na região nomeada enquanto tal. Neste ponto chegamos à nossa terceira tese: a fronteira é demarcada por ser entendida como diferente e por não estar enquadrada ou assimilada à visão de mundo hegemônica do enunciador.

Se a região de fronteira é delimitada a partir do modelo dominante, o poder de demarcá-la deve ser compreendido e assimilado enquanto um discurso legítimo, levando a uma ação concreta no mundo, e ainda, de alguma maneira, servir ao modelo dominante, como pudemos verificar na ação para o desenvolvimento da Amazônia. Em um texto acerca do tema região, balizado pelo conceito de Poder Simbólico, Pierre Bourdieu (1989, p.13 e 14) discutiu a criação de uma separação regional:

A etimologia da palavra região (regio), tal como a descreve Emile Benveniste, conduz ao princípio da di-visão, ato mágico, quer dizer, propriamente social, de diacrisis que introduz por decreto uma descontinuidade decisória na continuidade natural (não só entre regiões do espaço, mas também entre as idades, os sexos, etc.). Regere fines, o ato que consiste em "traçar as fronteiras em linhas retas", em separar "o interior do exterior, o reino do sagrado do reino do profano, o território nacional do território estrangeiro", é um ato religioso realizado pela personagem investida da mais alta autoridade, o rex, encarregado de regere sacra, de fixar as regras que trazem à existência aquilo por elas prescrito, de falar com autoridade, de pré-dizer no sentido de chamar ao ser, por um dizer executório, o que se diz, de fazer sobrevir o porvir enunciado.

De imediato, notamos uma forma diferente de perceber a região, descreve-a como um produto. Se é produto de uma formulação, ela não é fixa e nem, necessariamente, física, podendo ainda sugerir disputas em torno da demarcação, delimitação e utilização da região, que vai muito além das margens de qual- 
quer rio ou de qualquer montanha que apareça como marco divisório (o que é absolutamente arbitrário), porém, perfeitamente compreensível, se buscarmos a motivação que determinou tal fronteira. Ou seja,

Ninguém poderia hoje sustentar que existem critérios capazes de fundamentar classificações "naturais" em regiões "naturais", separadas por fronteiras "naturais". A fronteira nunca é mais do que o produto de uma divisão a que se atribuirá maior ou menor fundamento na "realidade" segundo os elementos que ela reúne, tenham entre si semelhanças mais ou menos numerosas e mais ou menos fortes. [...] Mas não é tudo: a "realidade", neste caso, é social de parte a parte e as classificações mais "naturais" apóiam-se em características que nada têm de natural e que são, em grande parte, produto de uma imposição arbitrária, quer dizer, de um estado anterior da relação de forças no campo das lutas pela delimitação legítima. (Bourdieu, 1989, p. 114-15)

Precisamos perceber quem é o elemento fundamental nessa demarcação: quem é o Rex, que, de acordo com Bourdieu, tem o poder de demarcar as regiões? Buscando a resposta em sua própria argumentação, o Rex, deve ser alguém investido com poder simbólico para impetrar tal violência. Não se trata de relacioná-lo, pura e simplesmente, à figura do Rei ou ao Estado, em sentido estrito.

A incorporação do conceito gramsciano de Estado Ampliado e da forma como se dá a construção da hegemonia nos permite situar a historicidade de construção da ideia de fronteira. Nesse sentido, a manutenção da ideia de desenvolvimento é resultado da construção hegemônica realizada na segunda metade do século XX, da mesma forma que a incorporação da sustentabilidade é resultado de uma operação semelhante, se bem que de forma secundária, pois as pressões da sociedade civil, parte do Estado Ampliado Gramsciano, construíram o adjetivo, sem, entretanto, conseguir modificar o substantivo.

A invenção da fronteira e das políticas públicas lá adotadas, seja para o desenvolvimento, seja para a sustentabilidade, não pode estar situada simplesmente numa perspectiva de Estado como a de Marx. Em Gramsci, apesar de o Estado não ser encarado como um mero comitê administrativo para os assuntos da burguesia, a noção de classe não desapareceu, mas tornou visível no embate político. Para que compreendamos a hegemonia-ditadura de um grupo sobre o restante da sociedade é necessário que percebamos o papel desse grupo dentro do processo social. O papel exercido no processo produtivo é fundamental para entender como se dá a sua direção-dominação e suas atitudes (políticas, culturais e econômicas). A partir da identificação do grupo hegemônico podemos estabelecer como esse articulará suas políticas para a manutenção de sua hegemonia. A utilização dos textos gramscianos implica considerar o Estado, sobretudo, de forma relacional e não como um todo monolítico sem disputas internas, sem frações de classe em luta (Gramsci, 1968). É dessa forma que o conceito de sustentabilidade adentrou as políticas de desenvolvimento para a Amazônia e, hoje, o ambiente é alvo intenso de disputas no interior do Estado. O Estado assume então, para além de um monopólio da coerção física legítima, uma face que 
extrapola a clausura da institucionalidade. Ao considerá-lo de forma ampliada sociedade civil e sociedade política, com diferentes grupos na disputa pela fala hegemônica. É assim que perpassam, nesse mesmo Estado, agências nacionais e internacionais, que estabelecem pressões para a mudança de rumos nas políticas ambientais e, em particular, na ação do Estado na Amazônia.

Mas de que forma esse aporte em Gramsci e Bourdieu poderá nos ajudar a pensar a produção da representação de fronteira? Ao entender o Estado de forma relacional, as representações e discursos oriundos de grupos, que almejam ou detêm a hegemonia tendem a transformar particulares em visões de mundo válidas para outros estratos sociais. A representação da fronteira, como área a ser ocupada, apresenta-se como uma dessas construções. Tanto mais eficaz será a definição de fronteira, formulada por intelectuais orgânicos com capital simbólico suficiente para tal, quanto maior for o poder de direção (enquanto aparelho privado) de quem o formula. Se tal representação for elaborada a partir do Estado (aqui em sentido restrito), mais possibilidade terá de ser apropriado pelos diversos segmentos da sociedade civil e produzir práticas políticas e sociais, pois o grupo que o produziu, como detentor da hegemonia, tem a capacidade de extrapolar a particularidade de sua visão de mundo (seja pela direção, seja pela dominação).

Se retomarmos a noção de capital simbólico do seio do Estado, tal qual a definição de Bourdieu, temos:

O Estado é o resultado de um processo de concentração de diferentes espécies de capital, capital de força física ou de instrumentos de coerção (exército, polícia), capital econômico, capital cultural, ou melhor, de informação, capital simbólico, concentração que, enquanto tal, constitui o Estado como detentor de uma espécie de metacapital, com poder sobre outros tipos de capital e sobre seus detentores A concentração de diferentes tipos de capital (que vai junto com a construção dos diversos campos correspondentes) leva, de fato, à emergência de um capital específico, propriamente estatal, que permite ao Estado exercer poder sobre os diversos campos e sobre os diferentes tipos específicos de capital... (Bourdieu, 1996, p.99)

Se a representação de uma fronteira é produzida ou apropriada pelo Estado (o que também é possível), tal construção simbólica recebe um aporte de capital simbólico considerável, sendo capaz de gerar ações sobre o mundo de maior envergadura, podendo ser incluído aqui, como o exemplo, o Projeto Radambrasil, cujo mapeamento da Amazônia, amparado no fato de ser um trabalho científico de enorme envergadura serviu de base para ação sobre a fronteira.

Como vimos no princípio deste trabalho, as representações sobre a Amazônia, ou, apropriando-me de Bakhtin (1990), as significações sobre a Amazônia se alteraram ao longo do século XX. Tais alterações não foram aleatórias, são frutos de visões de mundo e de interesses, que se expressaram no plano do Estado. Isso acabou por conduzir o Estado a agir sobre o meio. Um exemplo disso pode ser percebido nas ações para o desenvolvimento e para a sustentabilidade, que tratamos nesse trabalho. A incorporação da defesa do ambiente tem força 
política, porém ainda é secundária. Todavia, a Amazônia tem sido locus de programas de desenvolvimento e principal bioma sendo defendido pelos partidários da sustentabilidade ambiental. Isto tem conduzido políticas na e para a região.

Se considerarmos que a construção da direção é histórica e se considerarmos que as relações de força e a capacidade de mudança podem ocorrer, podemos supor que as teses sobre a sustentabilidade ambiental possam tornar-se prioritárias. Perceber a Amazônia como objeto central dessas disputas poderia implicar uma reconfiguração da fronteira já ocupada. Ao observarmos as mudanças propostas para a alteração do código florestal, vemos em ação o resultado preliminar dessas possibilidades. Se as alterações no bloco do poder nos conduzirem para novas representações, apropriações e políticas de desenvolvimento para a região da fronteira, podemos sugerir nossa quarta tese: a delimitação da fronteira é volátil; logo, a fronteira é volátil. Ou seja, pode diluir-se no ar, ao sabor dos interesses em jogo da disputa pela hegemonia e pela significação.

Resta-nos ver qual será o resultado dessas ações e pressões políticas sobre a Amazônia. Aquilo que era o diferente antes de JK e dos governos militares sofreu intervenções para tornar-se igual (parte de um único todo, apesar de possuir papel distinto na divisão territorial do trabalho). A alteração de uma visão de mundo desenvolvimentista para outra que transforme a defesa ambiental na ordem do dia pode indicar, que ao tornar-se igual, ficou perigoso e não desejado. Não há como antecipar os resultados, mas, nos próximos anos, veremos se a Amazônia ainda é o outro ou já é o mesmo.

\section{Referências}

BAKHTIN, M. Marxismo e filosofia da linguagem. São Paulo: Hucitec, 1990.

BECKER, B. K. A (des)ordem global, o desenvolvimento sustentável e a Amazônia. In: CHRISTOFOLETTI, A. et al. (Org.) Geografia e meio ambiente no Brasil. São Paulo: Hucitec, 1995. p.47-64.

BECKER, B. K. et al. Fronteira Amazônica: questões sobre a gestão do território. Brasília: UNB/UFRJ, 1990.

BOURDIEU, P. O poder simbólico. Rio de Janeiro: Bertand Brasil, 1989.

Razões práticas. Sobre a teoria da ação. Campinas: Papirus, 1996.

BUCI-GLUKSMANN, C. Gramsci e o Estado. Rio de Janeiro: Paz e Terra, 1980.

CHARTIER, R. A história cultural. Entre práticas e representações. Lisboa: Difel, 1990.

DINIZ FILHO, L. L.; BESSA, V. C. Território e política: as mutações do discurso regionalista no Brasil. Estudos Históricos, Rio de Janeiro, v.8, n.15, p.27-37, jan.-jun. 1995.

FONTES, V. Capitalismo, exclusão e inclusão forçada. Revista Tempo, Rio de Janeiro, v.2, n.3, p.34-58, 1997.

FURTADO, C. Teoria e política do desenvolvimento econômico. São Paulo: Nacional, 1979. 
GARRIDO FILHA, I. O projeto Jari e os capitais estrangeiros na Amazônia. Petrópolis: Vozes, 1980.

GRAMSCI, A. Maquiavel, a politica e o Estado moderno. Rio de Janeiro: Civilização Brasileira, 1968.

LUXEMBURG, R. A acumulação de capital: contribuição ao estudo econômico do imperialismo. São Paulo: Nova Cultural, 1985.

MARTINS, J. S. Fronteira: a degradação do Outro nos confins do humano. São Paulo: Hucitec, 1997.

OLIVEIRA, A. U de. Amazônia: monopólio, expropriação e conflitos. Campinas: Papirus, 1993.

OLIVEIRA, F. de. Elegia para uma re(li)gião. São Paulo: Paz e Terra, 1977.

OLIVEIRA FILHO, J. P. O caboclo e o brabo. Encontros com a Civilização Brasileira, Rio de Janeiro, v.11, p.101-40, 1979.

ROSTOW, W. W. Etapas de um desenvolvimento econômico (um manifesto não comunista). Rio de Janeiro: Zahar, 1971.

VELHO, O. G. Capitalismo autoritário e campesinato. São Paulo: Difel, 1979.

RESUMO - O artigo procura construir uma abordagem teórica para se pensar a fronteira amazônica e suas atuais perspectivas, quando a discussão sobre desenvolvimento e sustentabilidade ambiental a colocam na ordem do dia. Partindo da análise de outras formulações acerca da fronteira amazônica e do processo de expansão sobre a mesma no final dos anos 1960, procuramos identificar as contribuições e os limites do conceito de fronteira adotado pelos autores. Mais do que identificar as ações sobre uma região de fronteira, buscamos teorizar sobre a construção do conceito, demonstrando que o mecanismo que constrói a fronteira e denomina uma região enquanto tal é um mecanismo de poder.

PALAVRAS-CHAVE: Amazônia, Fronteira, Desenvolvimento, Meio ambiente.

ABSTRACT - The paper intends to build up a theoretical approach in order to think the Amazon borders and its contemporary perspectives in a moment when development and environmental sustainability insert it in the debate. Departing from formulations about the theme and the process of frontiers' expansion in the 1960's, we identified the contributions and the limitations of the concept of borders adopted by the authors. More the identifying the actions over a border region, we theorised about the construction of a concept, demonstrating that a mechanism that builds up the border and names a region such as a "frontier" is a mechanism of power.

KErWORDS: Amazon, Frontier, Development, Environment.

Antônio Cláudio Rabello é professor do Departamento de História da Universidade Federal de Rondônia; doutor em Desenvolvimento Socioambiental pelo Núcleo de Altos Estudos Amazônicos, da UFPA. @ - antonio.rabello@pq.cnpq.br

Recebido em 10.12.2010 e aceito em 5.1.2011. 
